\title{
"Vamos lá curtir um bocado". A relação entre identidade sexual, violência e sexualidade em conflitos armados
}

"Let's Have a Bit of Fun": The Relationship between Sexual Identity, Violence and Sexuality in Armed Conflict Situations

"Viens, on va s'amuser un peu!». La relation entre l'identité sexuelle, la violence et la sexualité dans les conflits armés

\section{Gaby Zipfel}

Tradutor. Júlia Garraio

\section{(2) OpenEdition Journals}

Edição electrónica

URL: http://journals.openedition.org/rccs/4802

DOI: $10.4000 /$ rccs. 4802

ISSN: 2182-7435

Editora

Centro de Estudos Sociais da Universidade de Coimbra

Edição impressa

Data de publição: 1 março 2012

Paginação: 31-46

ISSN: 0254-1106

Refêrencia eletrónica

Gaby Zipfel, « "Vamos lá curtir um bocado". A relação entre identidade sexual, violência e sexualidade em conflitos armados », Revista Crítica de Ciências Sociais [Online], 96 | 2012, posto online no dia 15 fevereiro 2013, consultado o 14 novembro 2019. URL : http://journals.openedition.org/rccs/4802 ; DOI : $10.4000 /$ rccs. 4802

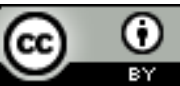




\section{“Vamos lá curtir um bocado". A relação entre identidade sexual, violência e sexualidade em conflitos armados}

Para decifrar a genealogia das formas de violência sexual nos períodos de entre-guerra, guerra e pós-guerra torna-se necessária uma análise das relações entre identidade sexual, violência e sexualidade. Os conflitos armados podem ser vistos como uma espécie de lupa que torna visíveis as definições de identidade sexual construídas através da legitimação da violência. Os crimes de violência sexual na guerra, vistos até hoje como fenómenos limite característicos de um estado de exceção, apontam, nesta perspetiva, para regularidades cuja função e forma podem variar, mas cujos pontos de referência radicam na expressão social do poder.

Palavras-chave: estudos sobre a mulher; feminilidade; guerra; masculinidade; violência; violência sexual.

O ser humano nunca é obrigado a agir com violência, mas pode sempre fazê-lo, nunca é obrigado a matar, mas pode sempre fazê-lo - individual ou coletivamente, em conjunto ou em separado - em todas as situações, a lutar ou a festejar - em diferentes estados de espírito, com raiva, sem raiva, com vontade, sem vontade, aos gritos ou em silêncio (em silêncio de morte) - com todos os fins imagináveis qualquer pessoa $[\ldots]$

PopITz (1986: 76)

À perturbação que a descrição do sociólogo Heinrich Popitz acerca do potencial de violência de qualquer ser humano provoca, contrapõe-se geralmente um consenso segundo o qual a violência é, em regra, ilegítima e sujeita a sanções. Nas considerações que se seguem, tentarei demonstrar que, no caso da violência sexual, é apenas com muito esforço que se consegue alcançar uma unanimidade igualmente inequívoca.

Antes de mais, deixo aqui algumas considerações sobre o contexto em que trabalho, o Instituto de Investigação Social de Hamburgo. Uma das 
três áreas de investigação do Instituto é dedicada à teoria e à história da violência, um tema com que o cânone clássico da teoria académica tem evidentes dificuldades em lidar. A génese e as especificidades da abordagem teórica do tema da violência, especialmente na Sociologia, são, elas próprias, objeto explícito dos debates do Instituto, como se pode acompanhar na nossa revista, a Mittelweg 36. No contexto destes debates, o objetivo é, cada vez mais, analisar em que medida determinadas formas concretas de violência materializam, através da ação, uma hierarquia da masculinidade e da feminilidade. A construção, corrente e influente, do casal de conceção patriarcal - a mulher vulnerável e o seu protetor masculino - parece, tal como no passado, tanto funcionar como escudo de proteção da autoimagem masculina de heroísmo, reservando, assim, para o ser do sexo feminino um estatuto de vítima e de objeto, como servir de legitimação para o exercício da violência.

Um olhar que perspetive as mulheres como sujeitos ativos em todas as situações, por um lado, e os homens como frequentemente feminilizados em atos de violência, por outro, aponta, antes de mais, para a arbitrariedade e para a função da construção de identidade sexual que conseguiu impor-se de forma tão duradoira na História ocidental.

As construções da identidade sexual são definidas essencialmente através do corpo.

Por mais insatisfatório que seja considerar o corpo como entidade historicamente imutável e evidente em si mesma, e por mais útil que se revele uma desconstrução discursivo-analítica das construções do corpo, de modo a superar a perceção de preconceitos limitadores, não deixa de ser necessário, e inclusivamente vital, compreender e tematizar, ao mesmo tempo, a existência factual do corpo e da respetiva perceção da dor num determinado ambiente histórico-cultural de experiência e de vida.

Geralmente, só se consegue falar com sentido sobre violência quando esta é localizada em relações de violência e, por sua vez, as relações de violência são sustentadas por relações de poder: um sujeito outorga-se o direito a uma ação violenta, no decorrer da qual o ator procura subjugar o alvo da violência como objeto. Portanto, como Popitz refere, estamos perante um poder de ferir, por um lado, e uma vulnerabilidade a ser ferido, por outro. A atribuição destas posições a uma identidade sexual - o homem com o poder de ferir e a mulher vulnerável a ser ferida - é sobejamente conhecida e é considerada, ainda com demasiada frequência, como uma constante antropológica derivada das pretensas particularidades de um sexo biológico.

Os atos de violência que aqui vou abordar visam por regra ferir um corpo e provocam dor, sofrimento, mas também humilhação. Menciono expressamente 
estas evidências e estes lugares-comuns porque, estranhamente, a teoria deixa-os muitas vezes na sombra. A afirmação de Popitz choca e inquieta não enquanto abstrato. A inquietação instala-se quando o não articulado - o corpo e a sua perceção da dor - são tidos em conta.

"O primeiro golpe", escreveu Jean Améry nas suas tentativas de lidar com a experiência de tortura nas prisões nacional-socialistas, "traz à consciência do preso que ele é impotente - e, desta maneira, contém já o essencial de tudo o que se segue. [...] O outro, contra o qual estou fisicamente no mundo e com o qual apenas posso estar enquanto ele não tocar a superfície da minha pele como fronteira, impõe-me com o golpe a sua própria corporalidade. Está sobre mim e com isso aniquila-me." E constata: "É como uma violação..." (Améry, 1977: 56).

É surpreendente. A figura de argumentação comum, que insiste contra a ignorância em relação ao aspeto da identidade sexual, apela: violação é tortura! Porém, tal como no passado, continua a ter de contar com a probabilidade de embater contra a ideia subconsciente e pertinaz de que violação e violência sexual são atos ambivalentes, nos quais as posições agressor-vítima são ambíguas.

De maneira pérfida subjaz a esta atitude um facto que constitui a especificidade da violência sexual e que tomo como ponto de partida para algumas considerações que aqui gostaria de fazer: a violência sexual não causa apenas dor à vítima, também representa potencialmente uma invasão da sua líbido. Escorre sangue, esperma é derramado, e choram-se lágrimas de dor, mas também de vergonha.

Os debates em torno da violência sexual, nomeadamente aquela que ocorre em conflitos armados, são permeados por considerações sobre se se trata de crimes de violência que se servem da sexualidade ou se se desfruta da sexualidade nestes crimes de violência. Receio que à primeira definição escape o alcance, o drama desta forma específica de uso da violência. O próprio violador - na medida em que usa o seu corpo, em rigor, o seu pénis - não pode deixar de ter excitação sexual, mesmo que o exercício da violência, e não o prazer sexual, seja o motivo do seu ato. O ato, por sua vez, inflige à vítima mais do que uma ofensa à sua integridade física - rouba-se potencialmente uma expressão de vida fundamental, a qual, assim se supõe geralmente, deveria ser positiva:

As estruturas sexuais da vítima e do torturador estão envolvidas na psicodinâmica desta interação, e a vítima experimenta a tortura como sendo dirigida contra a imagem sexual que ele ou ela tem do seu corpo e contra a sua identidade sexual com o objetivo de as destruir. Assim, a parte essencial do efeito traumático e danificador da 
identidade da tortura sexual é o sentimento de se estar a ser cúmplice de uma situação ambígua que contém tanto elementos agressivos como libidinosos de uma natureza confusa. (Inger Agger e Soren Buus Jensen, apud Skjelsbaek, 2001: 220)

No caso da coreana Kim Young Suk, uma das vinte mil chamadas "mulheres de conforto" que o exército japonês escravizou sexualmente na Segunda Guerra Mundial, dificilmente se pode presumir que o violador tenha conseguido excitá-la libidinosamente à força. Suk descreve como o oficial Nakamora a tratou:

'Ó miúda coreana, és bonita, vamos lá curtir um bocado'. Mas eu só tinha doze anos e não fazia ideia do que significava 'Vamos lá curtir um bocado'. Nakamora tirou o pénis para fora, despiu-me e tive tanto medo. Obrigou-me a deitar-me no chão e feriu-me com a baioneta e eu sangrei. Despiu-me as calças e violou-me até eu sangrar. ${ }^{1}$

Podemos concluir deste relato que o oficial Nakamora "curtiu" do mesmo modo tanto a crueldade corporal e verbal como o ato sexual da penetração. A presunção que exprime de que a vítima também "curtiria" não reflete, como se poderia supor, puro cinismo.

"One, two, three, four. Every night we pray for war. Five, six, seven, eight. Rape Kill. Mutilate” (exemplo citado em Askin, 1997: 377). Esta lengalenga martelada no treino dos fuzileiros norte-americanos contém o equivalente da tríade "Blood, Sperm and Tears" e, logo na fase da formação dos militares, promete como diversão da guerra: violar, matar, ferir. Não devemos supor que os recrutas tomam à letra esta perspetiva de diversão da guerra. Não obstante, este e outros exemplos idênticos do jargão militar indicam que a tese, segundo a qual a associação do prazer sexual e do prazer no exercício da violência apenas se gera através da brutalização no decurso da guerra, dificilmente se aplica à realidade. Assim, Cooper, um GI norte-americano estacionado no Reino Unido durante a Segunda Guerra Mundial, pergunta à sua vítima de violação: "Porque é que não falas comigo? Aqui todas as raparigas fazem isso", para a seguir a ameaçar: "Se não me deres o que eu quero, estrangulo-te". Antes de, finalmente, a deixar partir, após consumada a violação, pergunta-lhe se ela gostaria de ir dançar com ele na semana seguinte. Porter, um companheiro, bate na sua vítima até ela ficar inconsciente para ter o que quer. Depois, ajuda-a a vestir-se, dá-lhe dinheiro e pergunta-lhe onde fica a cabine telefónica mais próxima,

\footnotetext{
${ }^{1}$ Gravação de um depoimento no Tribunal de Tóquio. Tradução a partir do inglês.
} 
pois tem de encontrar o caminho de volta para Kingsclere. ${ }^{2}$ Não se trata aqui de um escalar da violência numa zona de combate, não estamos aqui perante soldados embrutecidos pelos combates; trata-se antes, maioritariamente, de jovens soldados que serviam em unidades de abastecimento.

"A violação não é privada nem pública, e é ambas as coisas em simultâneo: com a sua ajuda traça-se e controla-se a fronteira entre ambos os campos" (du Toit, 2007: 25). É o que se verifica, de facto, tanto em cenários civis como em militares.

A minha proposta é que uma descrição densa de atos de violência sexual deve rastrear as linhas que definem estes atos de violência em tempos de paz, de guerra e de pós-guerra. Ainda que a violência sexual não só aumente substancialmente na guerra, como também desempenhe funções específicas nesse contexto, ela não surge sem premissas vindas dos tempos de paz, ou, melhor, dos períodos de entre-guerras, e não se esgota depois da guerra. As práticas da guerra, enquanto chamado estado de exceção, e as práticas de violência sexual vividas enquanto permissividade têm de fazer parte das linhas desta descrição, pois inscrevem-se no potencial de experiências e de ação de uma sociedade, sendo transmitidas de geração em geração.

Uma vez que, na vida civil, a associação entre o exercício maciço de violência e o prazer sexual é, apesar de tudo, ainda dominantemente considerada patológica, não deixa de surpreender que, na guerra, esta associação possa ser considerada, de um modo relativamente incontestado e persistente, como sendo "combat effective", especialmente após operações bélicas bem-sucedidas. $\mathrm{O}$ antigo oficial Yoshio Suzuki relatou o seguinte perante o Tribunal de Crimes de Guerra de Tóquio:

Como comandante de uma unidade de artilharia, fui eu próprio que, depois de uma operação em 1944, autorizei os soldados a fazerem "o que lhes apetecesse". Num grupo de mulheres mais velhas dei com uma de cerca de 30 anos. Mandei as outras embora - ela tentou escapulir-se pelas casas-de-banho. Vê-la assim fez aumentar a minha excitação sexual. Despi-a, ela estava nua, e violei-a brutalmente, bati-lhe com a minha arma. Ela não conseguia defender-se, tremia, a cara branca, muda, obedecia-me sem me contrariar. ${ }^{3}$

Numerosas declarações de soldados comprovam que as ações de combate e o exercício da violência até matar funcionam, de facto, como

\footnotetext{
${ }^{2}$ Casos descritos em Lilly (2007: 54).

3 Yoshio Suzuki, depoimento perante o Tribunal Internacional de Mulheres para os Crimes de Guerra de Escravidão Sexual cometidos pelos Militares do Japão. Tradução do inglês.
} 
estímulo sexual (Baker, 1981; Greiner, 2007). Neste caso, o medo da vítima faz aumentar ainda mais a excitação do agressor. Deveria analisar-se mais de perto em que medida o medo sentido pelo agressor - medo de perda de controlo, medo de perder a vida em combate -, por sua vez, se descarrega ativamente na agressão, sobretudo contra mulheres. Voltarei ainda a esta questão.

$\mathrm{Na}$ seguinte descrição de um veterano do Vietname, o ódio e a frustração funcionam como estímulo sexual:

Ela estava a chorar. Acho que era virgem. Tirámos-lhe as calças e apontámos-lhe uma arma à cabeça... Eu estava a possuir o corpo dela à força. Os outros gajos estavam de pé à volta dela com as espingardas, enquanto eu a fodia. Baby-san, gritava ela. Então um gajo encostou-lhe uma espingarda à cabeça e puxou o gatilho só para a fazer desaparecer... Isto era o ódio, a frustração... (testemunho citado em Baker, 1981: 211)

As declarações de agressores sugerem que na violência sexual também se pode descarregar misoginia no objeto despersonalizado. Assim, um violador sérvio descreve a sua vítima, que já tinha sido violada por outros vinte homens, com as seguintes palavras: "o cabelo dela [estava] pegajoso, ela metia nojo e estava cheia de esperma." Depois da violação, matou-a "com cinco balas na barriga" (caso descrito em Pohl, 2004: 9).

Já depois da Primeira Guerra Mundial (paralelamente aos debates em torno da chamada histeria de guerra), tinha sido pontualmente abordada a transformação que a sexualidade dos soldados tinha sofrido através da brutalidade da guerra, que provocara não só impotência mas também uma associação permanente de sensações sexuais a atos de violência maciços (prazer de matar). Jonathan Shay, um terapeuta norte-americano que tratou veteranos do Vietname, também descreveu consequências semelhantes da guerra no seu livro Achilles in Vietnam (Shay, 1998).

Nos últimos anos tem sido documentado, com cada vez maior frequência, que a violência sexual também é praticada por membros de forças de manutenção de paz. Deveria ser investigado com mais precisão em que medida estas situações devem ser consideradas consequência de crimes praticados em guerras precedentes ou um fenómeno autónomo. O caso Rhongi, um membro das forças de manutenção de paz na antiga Jugoslávia que violou e assassinou premeditadamente uma albanesa kosovar de onze anos, mostra como também neste campo a violência sexual é por vezes acompanhada de brutalidade extrema: 
Rhongi tinha contado a um soldado que planeava apanhar uma rapariguinha e violá-la, mas que depois tinha de a matar para se safar; ia deitar as culpas para cima dos sérvios. (Lilly, 2007: 32)

Visivelmente, este membro de uma força de manutenção de paz confessa, sem qualquer problema, satisfazer um desejo sexual deste tipo e apenas se preocupa com a forma de escapar às sanções possíveis para o seu ato. O problema parece ter solução: mata a vítima, a testemunha do crime. A ideia que tem de si próprio como peacekeeper parece não ser abalada pelo caso.

A guerra e a masculinidade confundem-se tão intimamente no discurso quotidiano que, até ao momento, nem a entrada das mulheres no domínio masculino das forças armadas nem as transformações gritantes por que passou nas últimas décadas o exercício da guerra, que já nada tem a ver com o mito da heroica luta corpo a corpo, conseguiram abalar tal perceção.

A associação entre sexualidade e violência na guerra não é de forma alguma tabuizada, como frequentemente se afirma; pelo contrário, na propaganda de guerra ou em subtextos como as narrativas de guerra, está explicitamente presente como a consequência natural do estado de exceção que é a guerra, ou como dano colateral. Ao mesmo tempo parece, porém, escapar a um debate público e teórico.

Também a tematização pública e, sobretudo, o escândalo perante a revelação de crimes de violência sexual em conflitos violentos nas últimas décadas ${ }^{4}$ continuam, tal como no passado, marcados pela hesitação em querer averiguar a interdependência entre estas manifestações de carga afetiva.

A associação entre guerra e violência como algo inevitável, porque inerente à natureza das coisas, é tida como tolerável desde que - idealmente produza uma forma "honrada" e delimitada do exercício da violência, controlada por regras e acordos.

“Apenas poucos estão preparados”, escreve Inger Skjelsbaeck em Sexual Violence and War "para analisar com precisão os mecanismos que produzem o atacante. Talvez por medo de terem de constatar que a possibilidade de cometer atos idênticos é um potencial que todos trazemos em nós." (Skjelsbaeck, 2001: 212). Não foi apenas com o caso de Lyndie England que fomos confrontados com o facto de que as mulheres pertencem também

${ }^{4}$ As contradições da tematização e da "destematização" são analisadas em Stanley e Feth (2007). 
potencialmente a estes "todos". Em Kelly Dawn Askin encontram-se os seguintes exemplos:

Elas despiram um homem, mandaram o resto de nós levantar-se e obrigaram-nos a ter sexo oral com ele, que era também um preso. Eram duas ustachas, irmãs, guardas prisionais que gostavam de nos obrigar a fazer estas coisas. (Askin, 1997: 270)

Exibiam prisioneiros dos sérvios nus enquanto, de fora, mulheres sérvias se despiam à frente deles. Quando um dos presos tinha uma ereção cortavam-lhe o pénis. (Askin, 1997: 270)

No entanto, a abordagem dos média ao caso England tornou claro como uma agressora do sexo feminino pôde ser utilizada, sem qualquer hesitação, para mostrar a violência sexual como fenómeno de exceção, como comportamento anómalo de mulheres e, na melhor das hipóteses, de agressores patológicos. ${ }^{5}$

$\mathrm{O}$ argumento segundo o qual a descrição pública e detalhada de ataques sexuais funciona como pornografia e agride adicionalmente as vítimas - argumento que foi repetido hipocritamente neste contexto, apesar de $\mathrm{Abu}$ Graib ter sido, de facto, objeto reiterado de reencenações pornográficas -, não problematiza uma sexualidade que se serve da violência desta forma, mas desloca o momento vergonhoso do ato do agressor para a vítima. Por trás do pretexto de querer proteger as vítimas de uma exposição renovada, esconde-se frequentemente uma atribuição da culpa às mulheres enquanto sujeitos femininos que transgridem as suas fronteiras e a cujos encantos os homens, desamparados, estão potencialmente expostos.

Todavia, negar a humilhação por que passa a vítima redunda em prolongar o seu sofrimento. Os relatos de afetados/as mostram como é essencial para eles/as saberem se o seu meio social reconhece o que lhes aconteceu enquanto sujeitos, incluindo a humilhação, como sendo uma injustiça, e se atribui esta ao agressor ou estigmatiza a vítima como objeto vergonhoso e desonrado. Louise du Toit argumenta:

Ao continuar a usar o termo "vítima”, não pretendo ferir os sentimentos daquelas que sobreviveram à violação, nem continuar a negar a capacidade de ação das mulheres e a sua subjetividade, ao acentuar a nossa impotência perante a violação. Julgo que temos de questionar de maneira crítica estes sentimentos em vez de simplesmente os afirmarmos. As vítimas de violação, muito mais do que outras vítimas (por exemplo,

\footnotetext{
5 Sobre esta questão, veja-se o estudo muito informativo de Oliver (2007).
} 
de acidentes de carro), rejeitam as associações de impotência atribuídas ao termo "vítima" porque é esta mesma impotência que está no cerne das feridas e da humilhação da violação. Assim, é mais importante abordar a raiz do problema (falta de subjetividade política e de capacidade de ação por parte das mulheres) em vez de nos satisfazermos com mudanças linguísticas superficiais. Uma pessoa não se torna sobrevivente negando em que medida se foi vítima. De facto, uma tal recusa estoica da vitimização, com ênfase na capacidade de ação e de resistência da vítima, pode bem, inadvertidamente, impedir estudos aprofundados como este, que pretendem analisar em que medida certas crenças sociais generalizadas estão na base de uma ética da violação. (du Toit, 2007: 4s.)

Uma parte nada insignificante dos esforços para controlar ou operacionalizar o poder de agredir é utilizada para ocultar a vulnerabilidade da pessoa do sexo masculino através da expressão ativa do seu poder de agressão contra a pessoa do sexo feminino ou efeminada, tanto na paz como na guerra. Sobretudo na guerra, o palco onde a masculinidade é construída de maneira mais acentuada e as suas características são mais exigidas, revela-se, todavia, ao mesmo tempo, de modo evidente, como a construção da masculinidade é realmente frágil. O combatente, a quem é exigida e simultaneamente concedida a disposição para matar (poder de agressão), tem de se confrontar simultaneamente com a sua vulnerabilidade, com a possibilidade de ser morto. O sexo revela-se aqui como "categoria de conflito" (Knapp, 2001): as ambivalências dolorosas no lidar com o próprio medo e as próprias fraquezas devem ser resolvidas no sentido duma variante invulnerável de masculinidade, de hipermasculinidade artificial (Bereswill, 2006: 244). Uma variante de masculinidade que, para fazer sentido, tenta desembaraçar-se totalmente do oposto feminino - uma tentativa que, por exemplo, durante e depois da Primeira Guerra Mundial foi elaborada de maneira especialmente drástica por Ernst Jünger, para quem a experiência da guerra se torna um substituto orgiástico e erótico da mulher. Uma outra variante consiste em escapar à subjugação através da violação de um oposto.

Para se conseguir a instrumentalização militar do ato de violação, no sentido de aumentar a disposição dos soldados para lutar e matar, é também necessário, nesta utilização da violência, um regulamento que imponha limites. Os atos ocasionais, voluntários e individuais, que são sempre previsíveis e com os quais se conta à partida, são, por princípio, punidos. Se há punição de facto, depende da avaliação dos comandantes militares sobre se se trata, ou não, de um ato eficaz para o combate. O cálculo militar de libertar e empregar o potencial de violência dos soldados para combater o inimigo e os motivos dos soldados para se tornarem violentos sexualmente não coexistem 
sem tensões. Podem, como no caso seguinte, citado por Johanna Bourke, opor-se de maneira grotesca:

Durante o massacre de My Lai, no dia 16 de março de 1968, durante o qual se violaram e mataram mulheres da maneira mais cruel, o tenente William L. Calley ficou fora de si, como mais tarde recordou nas suas notas autobiográficas "Body Counts", quando deu com o soldado Dennis Conti a obrigar uma jovem mãe vietnamita a fazer-lhe sexo oral. Ordenou-lhe que vestisse "o raio das cuecas" e reflete sobre o que o tinha irritado tanto na cena: "Violação: no Vietname é uma coisa muito comum... Acho que muitas raparigas prefeririam ser violadas a ser mortas. Então porque é que eu estava a ser tão intransigente com isto? Porque: se um soldado estiver a ter um broche, não está a fazer o seu trabalho. Não está a destruir o comunismo... No entanto, a nossa missão em My Lai não era pervertida. Era simplesmente "Ir e destruir aquilo"... Nenhuma diferença: se o soldado estiver a lucrar, não está a fazer o trabalho pelo qual lhe estamos a pagar. Não está a ser eficiente em combate. (Bourke, 1999: 173)

Dennis Conti, que achava poder exercer o seu direito aos despojos de guerra e a divertir-se sexualmente, tinha-se enganado: esperava-se dele que usasse a sua capacidade para o exercício da violência sexual de maneira eficaz para o combate.

Também para o general norte-americano Patton se trata de impor limites, não de punir o delito em si: "Disse-lhes então que, apesar dos meus esforços diligentes, haveria inevitavelmente algumas violações e que queria ter os pormenores o mais cedo possível para que os infratores fossem devidamente enforcados." Não obstante, constata de maneira lapidar noutra ocasião: "Se um soldado não foder, não luta." (apud Lilly, 2007: 29).

As guerras que aqui estão a ser tidas em conta como palcos de violência sexual, guerras do século XX e do início do século XXI, distinguem-se não apenas por uma totalitarização da organização bélica, mas também por um crescente desaparecimento de limites para a mesma, o qual emerge com particular clareza em guerras assimétricas. A distinção clássica entre a frente interna e a frente da guerra tornou-se obsoleta: as constelações dos beligerantes e os teatros de guerra alteram-se. Há que analisar quais as consequências destas mudanças para a forma de violência bélica aqui em discussão.

As lógicas em que tradicionalmente se baseia a regulamentação da guerra orientam-se pela possibilidade de construir um campo de batalha sinóptico. Ulrich Bröckling dedica-se ao estudo deste campo de batalha e descreve-o antes de mais como um "espaço de contingência por excelência", como 
"zona de fricções... lugar da fortune, da oportunidade inesperada, da sorte que muda repentinamente". Neste espaço de contingência realiza-se "o 'duelo alargado' (Clausewitz) de vida e de morte, que, para conseguir produzir clareza e uma perspetiva superior, obriga "todos os atores a um máximo de cálculo estratégico e tático, a um emprego racional da força e a um uso eficiente da violência". São exigidas "operações preparadas e coordenadas minuciosamente, ... improvisação espontânea, comando e obediência, bem como iniciativa própria e autorresponsabilidade." Um desafio numa situação que é determinada por "afetos extremos - da paralisia do medo da morte até ao furor do êxtase do combate", afetos que "inibem a ação ou a desinibem e alteram a sua direção". Os que nela agem sofrem uma "experiência radicalizada de contingência", que "exige conceitos não menos radicais para o seu controlo", como as que se manifestam na rigidez das exigências de obediência e de táticas disciplinares militares. Bröckling descreve, por conseguinte, a ação militar como "gestão de contingências com o objetivo de alinhar todas as atividades com vista ao aumento do potencial de violência próprio e, por conseguinte, ao seu enfraquecimento no inimigo". Essa ação tem assim em conta "o limite inevitável, mas que nunca se consegue determinar previamente, de toda a planificação e organização", o qual "determina os esforços militares para controlar a ação individual e coletiva na guerra”. E continua assim:

Quem quer comandar não precisa apenas de poder, mas também de saber. E para conseguir lidar com as fricções ou para conseguir contorná-las, é preciso conhecê-las... Tem de se contar com o que escapa aos cálculos (Bröckling, 2003: 189s.)

O General Patton, mencionado acima, esforça-se por satisfazer justamente esta exigência.

O controlo normativo, as práticas disciplinares tradicionais, apoiadas por um apetrechamento moral e pela punição dos desvios, são os meios de autoridade militar utilizados. Um olhar sobre as práticas do treino militar mostra como estes instrumentos são radicalmente determinados por conceções de identidade sexual. Frank J. Barrett, professor norte-americano de gestão de sistemas, analisou, com base em entrevistas, "a construção da masculinidade hegemónica" através do exemplo dos fuzileiros norte-americanos (Barrett, 1999). A ideia de se ser hegemónico perante os outros é transmitida por um "treino para o ódio", ${ }^{6}$ em que o adversário é degradado como

\footnotetext{
${ }^{6}$ Sobre esta questão, ver o capítulo 6 ("Love and hate") de Bourke (1999).
} 
outro inferior, ameaçador, desprezível. ${ }^{7} \mathrm{O}$ feminino torna-se o cúmulo do outro, inferior e desprezível. Tanto a gíria dos soldados como a dos instrutores militares está repleta de sexismos. É evidente que desta maneira se pode construir um ódio real pelas mulheres, que não se manifesta apenas em situações de combate.

\section{Male Bonding/Exclusão de mulheres}

Jonathan Shay refere que o sistema de identidade sexual é transferido para o exército e que os papéis sociais assentes nessa identidade são redistribuídos nesse contexto: "Tal como as famílias, os exércitos são também instituições que criam um mundo. Ambos fomentam com êxito o respeito, a lealdade, o amor, a confirmação, a gratidão e a obediência dos seus novos membros" (Shay, 1998: 209).

A formação de grupos primários e de comunidades de companheiros (dois homens unem-se como unidade) desempenha um papel fundamental indispensável, como Bröckling também acentua:

O sentimento de, no campo de batalha, estarem entregues e impotentes face a uma máquina de destruição anónima e poderem ser mortos a qualquer momento [faz] os soldados voltarem-se para si próprios de maneira existencial. A certeza de ser parte de um grupo e de poder contar com os companheiros pode não conseguir eliminar esta experiência de atomização, mas, em certa medida, compensa-a um pouco... A interligação e o reforço recíproco das normas institucionais e das normas dos grupos primários revelam-se sobretudo na codificação da masculinidade. A exigência de ser um homem faz parte do que mais comummente se espera de cada soldado. Corresponde às conceções sociais relativas ao exército como instância de socialização, está inscrita como subtexto nos programas de treino militar e constitui também um elemento central do código de comportamento dos grupos primários. Estes constituem-se não apenas como comunidades de proteção e de solidariedade, mas também como ligas igualitárias de homens, que produzem a sua coesão através da desvalorização de supostas características femininas e que exteriorizam a libido homoerótica transformando-a em agressividade. (Bröckling, 2003: 197s.)

Esta agressividade, desejada militarmente, considerada vital para gerar a prontidão para a luta, dirige-se, com toda a intencionalidade, não apenas contra os combatentes inimigos, mas, tal como se verificou na Bélgica na

\footnotetext{
${ }^{7}$ Sobre o significado de este outro, ou melhor dito, de esta outra, inferior, ameaçadora, contra a qual se atua, ser na prática predominantemente feminina e o opositor masculino ser classificado como feminino, ver Pohl (2002).
} 
Primeira Guerra Mundial, em Nanquim, na antiga União Soviética, em Berlim, no Bangladeche, no Vietname, na ex-Jugoslávia, no Ruanda - a lista não é completa -, igualmente para violações em massa "combat effective", não só da população civil feminina mas também da masculina.

\section{Violência sexual contra homens}

A violência sexual em guerras contra homens faz parte dos "tabus mais bem guardados da nossa cultura" (Seifert, 2003: 243). Todavia, como mostram alguns exemplos, pode encontrar-se com regularidade.

Durante $o$ ataque a Nanquim, homens chineses foram violados analmente ou obrigados a praticar atos sexuais entre si enquanto os soldados se riam (Iris Chang, apud Mischkowski, 2006).

$\mathrm{Na}$ primavera de 2000, o New York Times relatava que prisioneiros do sexo masculino detidos pelas tropas russas num campo em Grozny, na Chechénia, tinham ouvido os gritos de homens a serem violados pelos seus captores. Foi relatado que os agressores davam nomes femininos às suas vítimas depois da violação (Lilly, 2007: 20).

Em Kelly Dawn Askin encontram-se declarações como as seguintes, da Bósnia-Herzegovina:

Eles [os soldados sérvios] levaram-nos para fora e espancaram-nos um após outro - torturaram-nos de todas as maneiras imagináveis. Agarraram dois irmãos e obrigaram-nos a ter relações sexuais... Obrigaram dois amigos a pôr o pénis na boca um do outro... Ouvimos através dos portões como mandavam os homens torturarem-se e violarem-se uns aos outros. (testemunho citado em Askin, 1997: 271)

Poderíamos ser tentados/as a supor que a discussão pública da forma de violência sofrida por estes homens conduziria a uma reprovação mais forte da violência sexual em geral. Essa suposição é contrariada pela objeção de Antjie Krogs, que relata que, no decurso dos processos da Comissão da Verdade e Reconciliação da África do Sul, os homens recusaram usar a palavra "violação" nos seus depoimentos. Declaravam terem sido penetrados analmente ou que lhes tinham introduzido barras de ferro. O comentário da autora: "Assim faziam da violação uma coisa de mulheres. Ao negarem a sua própria subjugação sexual à brutalidade masculina, aliam-se aos violadores e conspiram com eles contra as próprias mulheres, mães e filhas..." O termo "violação" é, segundo Krog, "reservado exclusivamente para a submissão sexual das mulheres e torna-se assim sexista no seu significado." (Krog, 1998: 182).

Os delitos de violência sexual aqui abordados são acompanhados por muitos outros maus-tratos que podem levar até ao assassínio das vítimas. 
A violência sexual não ocorre nem sem padrões e objetivos sociais, nem num vácuo social. Tem significados específicos respetivamente para os inimigos, as vítimas e os agressores.

De acordo com a autoproclamada missão do soldado, as mulheres devem ser protegidas, defendidas e mantidas afastadas dos combates: contudo, é precisamente isto que as torna também alvo de agressão. Elas simbolizam o próprio território, que deve ser defendido, e cuja profanação é particularmente humilhante. $\mathrm{O}$ corpo da mulher torna-se campo de batalha tanto para uma luta homem-a-homem como para uma luta contra o conjunto de uma comunidade étnica, cultural ou religiosa. A violência exercida sobre o sujeito feminino é omitida na narrativa da guerra. Assim, os relatos públicos de violações em massa na Bélgica durante a Primeira Guerra Mundial, que assustaram a opinião pública, tematizavam não tanto o sofrimento das mulheres, mas sobretudo, com claras intenções propagandísticas de ambos os lados, a humilhação da nação pelos inimigos embrutecidos. ${ }^{8}$

\section{Violência/ Desejo}

Por muito que a liderança militar procure, com seriedade, mas na maioria das vezes sem grande convicção (Greiner, 2007), recuperar a vassoura em que, como o aprendiz de feiticeiro da balada de Goethe, delegou poderes próprios, e por mais que tente realizar a sua tarefa de impor a ordem e impedir, com recurso à violência da ordem militar, "descarrilamentos" e manifestações de dissolução em situações precárias e difusas, raramente esses objetivos são atingidos. Mesmo medidas draconianas (enforcamento, trabalhos forçados perpétuos) não impediram, por exemplo, os militares norte-americanos utilizados no Reino Unido, na França e na Alemanha durante a Segunda Guerra Mundial de violarem mulheres "just for fun", na maior parte das vezes recorrendo a armas. ${ }^{9}$ Enquanto na França o estereótipo, vindo de gerações anteriores, da francesa sexualmente permissiva funcionou como licença para violar, na Alemanha atuaram também motivos de ódio e de vingança. Assim, um soldado que tinha visitado Dachau antes do ato de violação, argumentou que uma mulher ser despida por três americanos era uma ninharia em comparação com o que tinha acontecido no campo de concentração (Lilly, 2007: 136). Os delitos sexuais cometidos neste cenário, enquanto atos ocasionais e individuais, não tinham sentido militar e contrariavam a disciplina. Como tal, é verdade que foram punidos (ibidem: 29). Não obstante, estas tentativas de contenção disciplinar não

\footnotetext{
${ }^{8}$ Sobre esta questão ver Horne e Kramer (2004), Crauthamel (2008).

9 Sobre esta questão ver Lilly (2007).
} 
são reconfortantes, uma vez que não se dirigem de maneira decidida e rigorosa contra a prática da violência sexual.

No seu livro de memórias Seed of Sarah, a judia húngara Judith Magyar Isaacson descreveu de maneira acutilante como o comandante do campo de Lichtenau lhe ordenou um dia que o seguisse:

O comandante caminhava à minha frente nas suas calças de montar engomadas e botas pesadas. Segui-o instintivamente, de cabeça baixa, os olhos cravados no cascalho do caminho. Tive um reconhecimento súbito, como se no passado já tivesse seguido um senhor em tão muda obediência. Será que as mulheres herdam memórias de violação? Lembrei-me do mito do rapto das sabinas e da história da surtida de Hunor e Magor, os antepassados lendários dos Hunos e dos Magiares, para trazerem à força as suas mulheres. "A minha desgraça não é única", disse a mim mesma, "fui apanhada num rito ancestral de sexo e guerra." (Isaacson, 1990: 90).

\section{Referências bibliográficas}

Améry, Jean (1977), Jenseits von Schuld und Sübne. Stuttgart: Klett-Cotta.

Askin, Kelly Dawn (1997), War Crimes against Women. Prosecution in International War Crimes Tribunals. The Hague: Martinus Nijhoff Publishers.

Baker, Mark (1981), Nam. The Vietnam War in the Words of the Men and Women who Fought There. New York: Cooper Square Press.

Barrett, Frank J. (1999), „Die Konstruktion hegemonialer Männlichkeit in Organisationen: Das Beispiel der US-Marine“, in Christine Eifler e Ruth Seifert (orgs.), Soziale Konstruktionen - Militär und Geschlechterverbältnis. Münster: Westfälisches Dampfboot, 71-93.

Bereswill, Mechthild (2006), „Männlichkeit und Gewalt. Empirische Einsichten und theoretische Reflexionen über Gewalt zwischen Männern im Gefängnis“, Feministische Studien, 24(2), 242-255.

Bourke, Joanna (1999), An Intimate History of Killing. Face-to-Face Killing in Twentieth-Century Warfare. London: Basic Books.

Bröckling, Ulrich (2003) „Schlachtfeldforschung. Die Soziologie im Krieg“, in Steffen Martus, Marina Münkler e Werner Röcke (orgs.), Schlachtfelder. Codierung von Gewalt im medialen Wandel. Berlin: Akademie Verlag.

Crauthamel, Jason (2008), „Male Sexuality and Psychological Trauma: Soldiers and Sexual ,Disorder' in World War I and Weimar Germany“, Journal of the History of Sexuality, 17(1), 60-84.

Greiner, Bernd (2007), Krieg obne Fronten. Die USA in Vietnam. Hamburg: Hamburger Edition.

Horne, John; Kramer, Alan (2004), Deutsche Kriegsgreuel 1914. Die umstrittene Wabrheit. Hamburg: Hamburger Edition. 
Isaacson, Judith Magyar (1990), Seed of Sarah. Memoirs of a Survivor. Urbana: University of Illinois Press.

Knapp, Gudrun Axeli (2001), „Dezentriert und viel riskiert. Anmerkungen zur These vom Bedeutungsverlust der Kategorie Geschlecht“, in Gudrun Axeli-Knapp e Angelika Wetterer (orgs.), Soziale Verortung der Geschlechter. Gesellschaftstheorie und feministische Kritik. Münster: Westfälisches Dampfboot.

Krog, Antjie (1998), Country of my Skull. Johannesburg: Random House.

Lilly, Robert (2007), Taken by Force. Rape and American GI's in Europe during World War II. New York: Palgrave Macmillan.

Mischkowski, Gabriela (2006), „Sexualisierte Gewalt im Krieg - Eine Chronik“, in medica mondiale e.V., Karin Griese (org.), Sexualisierte Kriegsgewalt und ibre Folgen. Handbuch zur Unterstützung traumatisierter Frauen in verschiedenen Arbeitsfeldern. Frankfurt am Main: Mabuse-Verlag.

Oliver, Kelly (2007), Women as Weapons of War. Iraq, Sex and the Media. New York: Columbia University Press.

Pohl, Rolf (2002), „Massenvergewaltigung. Zum Verhältnis von Krieg und männlicher Sexualität“, Mittelweg 36, 2, 53-75.

Pohl, Rolf (2004), Feindbild Frau. Männliche Sexualität, Gewalt und die Abwebr des Weiblichen. Hannover: Offizin.

Popitz, Heinrich (1986), Phänomene der Macht. Tübingen: Mohr.

Seifert, Ruth (2003), „Im Tod und Schmerz sind nicht alle gleich: Männliche und weibliche Körper in den kulturellen Anordnungen von Krieg und Nation“, in Steffen Martus, Marina Münkler e Werner Röcke (orgs.), Schlachtfelder. Codierung von Gewalt im medialen Wandel. Berlin: Oldenbourg Akademieverlag.

Shay, Jonathan (1998), Achill in Vietnam. Kampftrauma und Persönlichkeitsverlust. Hamburg: Hamburger Edition.

Skjelsbaek, Inger (2001), „Sexual Violence and War: Mapping out a Complex Relationship“, European Journal of International Relations, 7(2), 211-237.

Stanley, Ruth; Feth, Anja (2007), „Die Repräsentation von sexualisierter und Gender-Gewalt im Krieg. Geschlechterordnung und Militärgewalt“, in Susanne Krasmann e Jürgen Martschukat (orgs.), Rationalitäten der Gewalt. Staatliche Neuordnungen vom 19. Bis zum 21. Jabrbundert. Bielefeld: Transkript.

du Toit, Louise (2007) „Feminismus und die Ethik der Versöhnung“, Mittelweg 36, 3, 4-30. 